\title{
“Vamos ver como é pra contar com'foi”: uma análise do códice 482 do Mosteiro de São Bento da Bahia
}

\author{
Tamires Alice Nascimento de Jesus ${ }^{*}$ \\ Lívia Borges Souza Magalhães \\ Alícia Duhá Lose
}

Resumo: Quando se está diante de um universo diferente do que se está acostumado, é comum a busca por caminhos que facilitem a compreensão das tradições, dos costumes arraigados daquela cultura, do modo de funcionamento da língua e outros fatores que delineiam o patrimônio cultural imaterial de determinada comunidade. Essa premissa permite a crença de que um monge, não conhecedor da cultura em que fora inserido, terminou cunhando um aparato constituído por várias expressões cotidianas empregadas provavelmente entre os séculos XIXXX, registradas sob o título Notas. Com o objetivo de desvendar - por intermédio da escrita - a história desse códice, que poderá contribuir para estudos linguísticos, discursivos, lexicais, culturais, semânticos e históricos, será realizada a descrição, inventariação, análises intrínseca e extrínseca e edição desse manuscrito partindo dos domínios da Filologia e das ciências do Léxico, além de contar com o apoio da Paleografia, Diplomática e Codicologia.

Palavras- chave: Levantamento lexical; Filologia; Cultura.

Resumen: Cuando estás en un universo diferente de lo que se esta acostumbrado, es común a busca por camiños que faciliten la comprensión de las tradiciones, las costumbres arraigadas de aquella cultura, el modo de funcionamiento de la lengua y otros factores que señalan el patrimonio cultural inmaterial de una determinada comunidad. Esa premisa permite la creencia de un monje no conoedor de la cultura en que fuera inserto, terminou hacendo un soporte constituido por varias expresiones de uso cotidiano, probablemente, entre los siglo XIX-XX, grabados bajo el título Notas. Con el intento de descubrir- por intermedio de la escritura - la historia de esse códice, que puede contribuir para estudos linguisticos, discursivos, lexicais,culturales, semanticos e historicos, ha ser realizada la descripción, inventario y análisis de la seguridad y la edición de este documento a partir de la los campos de la filología y el Léxico científico, además de tener el apoyo de Paleografía, Diplomática y Codicología. Palabras-llave: Alzamiento Lexical. Filología. Cultura.

\footnotetext{
* Graduanda do curso de Letras Vernáculas da Universidade Federal da Bahia (UFBA), pesquisadora do Mosteiro de São Bento da Bahia e bolsista de iniciação científica (PIBIC/ CNPQ).

Mestranda em Letras na área de Língua e Cultura pela Universidade Federal da Bahia (UFBA), pesquisadora do Mosteiro de São Bento da Bahia e bolsista da CAPES.

- Doutora em Letras e Linguística pela Universidade Federal da Bahia (UFBA), coordenadora e pesquisadora da Faculdade São Bento da Bahia, profa. adjunta da Universidade Federal da Bahia.
} 


\section{Introdução}

Como modo de demonstrar os domínios que esta pesquisa envolve, iniciaremos este trabalho evidenciando a relação existente entre a Filologia e Estudos Lexicais, duas grandes áreas do saber que norteiam o trabalho em vigor. Para tal, as considerações de Almeida (2006, p. 230) são bastante apropriadas: “[...] o estudioso de léxico que pode ser o próprio filólogo, precisa, ao considerar uma dada língua, em qualquer sincronia, ter como ponto de partida, para realização de seus estudos, um texto fidedigno.'

Iniciaremos este trabalho situando o objeto de estudo, em seguida apresentaremos o desenvolvimento da pesquisa para, enfim, expor os resultados parciais, o percurso traçado e as hipóteses levantadas.

\section{Situando o objeto: uma questão terminológica}

O Códice $482^{1}$, que é conhecido como um glossário entre os monges beneditinos do Mosteiro de São Bento da Bahia, apresenta um conjunto de expressões utilizadas no cotidiano, provavelmente entre os séculos XIX-XX. Ele traz, ainda, conhecimentos do senso comum, a exemplo dos remédios caseiros; e algumas reflexões acerca das etapas da vida do ser humano.

Em relação à terminologia, o termo glossário merece alguns comentários. Para o fazer, parece interessante observar alguns pontos da história da Lexicografia, que conforme Haensech (1982, p. 24):

[...] renació esta disciplina en los países latinos en la Edad Media, cuando la lengua vulgar ya apresentaba tantas diferencias con el latín (lengua de la cultura, de la liturgía y del derecho), que se hizo necesario explicar las palabras difícilmente comprensibles por meio de glosas [...] se pueden distingir glosas interlineales y marginales [...] Señalemos de paso que aún en la actualidad se usan, en ciertos textos escolares escritos en lengua extranjera, glosas marginales para explicar al alumno palabras y giros dificiles. Cuando las glosas aparecen en forma alfabética o sistemática, al final de um texto, hablamos de 'glosario'. Hoy en día, el término 'glosario' se utiliza em lexicografía con dos acepciones distintas: Repertorio de voces

${ }^{1} \mathrm{O}$ códice 482 recebe esse nome tendo em vista que essa é a numeração de identificação dele no inventário do Arquivo Histórico do Mosteiro de São Bento da Bahia, local onde tal manuscrito é salvaguardado. 
destinado a explicar um texto medieval o clásico, la obra de un autor, un texto dialectal, etc. Repertorio de palabras, en muchos casos de términos técnicos (monolíngüe o plurilíngüe) que no pretende ser exhaustivo, y en que la selección de palabras se ha hecho más o menos al azar [...].

A segunda acepção apresentada nos permite afirmar que o Códice 482 seja um glossário, no entanto, é preciso atentar para um detalhe: ele não se refere a um texto específico, como geralmente ocorre com um glossário, conforme diz Muller (1968, p. 35): “[...] o glossário lato sensu resulta do levantamento das palavras-ocorrências e das acepções que têm num texto manifestado [...]”, mas, se pensarmos que o códice em questão apresenta, ao lado do significante uma única possibilidade de significado que seja condizente naquela expressão, mesmo não pertencendo a um texto específico, ele possui uma restrição significativa que direciona o contexto de uso.

Barbosa (1996, p. 36), ao diferenciar um glossário de um vocabulário, afirma: “[...] o glossário pretende ser representativo da situação lexical de um único texto manifestado [...] numa situação de enunciação e de enunciado, numa situação de discurso exclusivas e bem determinadas [...]."

Sendo assim, a representação da situação lexical bem definida é suficiente, pois se trata de expressões, e esse ponto encerra a possibilidade de outras significações. Se utilizamos uma construção como: "Ter a pulga atrás da orelha”, por exemplo, não será permitida uma interpretação diferente de desconfiança ou culpabilidade, a menos que a análise seja feita por um falante não nativo que, por esse motivo, não possui em seu léxico mental o significado contextualizado da expressão.

Se tomarmos como base o posicionamento de Nunes (2006, p. 46), perceberemos que houve um momento que o glossário deixou de ser, necessariamente, ligado ao texto:

Os glossários, que se multiplicaram a partir do século VI, se desenvolvem com a prática de decodificação e interpretação de textos gregos e latinos na escola. Numa primeira fase foram editados à margem ou no meio do texto. Numa segunda fase, organizavam-se em ordem alfabética ou por domínios temáticos. A lexicografia, então ligava-se a textos, que se comentavam e interpretavam. Esse processo, levado adiante, resultará na autonomia do glossário. Este se desprenderá do texto e passará a ser usado no ensino de língua. (grifo nosso) 
Logo, a utilização da terminologia glossário aplicada ao Códice 482 parece propícia, mesmo não tendo um texto como ponto de partida. Essas particularidades serão exploradas mais adiante. Seguiremos com reflexões a respeito das expressões registradas no documento.

\section{As expressões}

Inicialmente pensávamos que todas as expressões registradas no códice eram idiomáticas, mas, com o desenvolvimento da pesquisa e o estudo mais descobrimos que havia uma variedade de locuções e não se tratava apenas de idiomatismos. Para apresentar algumas estruturas que foram detectadas necessidade de classificação dos itens lavrados se manifestou; para esse fim, tomamos como base a proposta de Fulgêncio (2008, p. 102)

[...] passarei a chamar todos os blocos fixos e idiomáticos de expressões fixas (EFs). $\mathrm{Na}$ categoria das expressões fixas entram também casos de colocações (collocations), expressões transparentes cristalizadas, provérbios, fórmulas sociolingüísticas e EFs mistas (léxico + sintaxe): todos são blocos idiomáticos e todos são armazenados conjuntamente na memória do usuário da língua. "Expressão fixa" é então o nome dado a qualquer grupo de palavras convencionais memorizado em conjunto, que por isso constitui uma unidade lingüística. (grifos do autor)

As principais características das expressões idiomáticas são o caráter semântico não composicional e $\mathrm{o}$ fato de fazerem parte da memória lexical do falante (FULGÊNCIO, 2008, p. 168)

Acordado que se trata de expressões fixas, apresentamos as ocorrências registradas no códice e suas definições.

\subsection{Expressões Idiomáticas}

Figura 1: Fragmento do fólio $11 \mathrm{r}^{\mathrm{o}}$

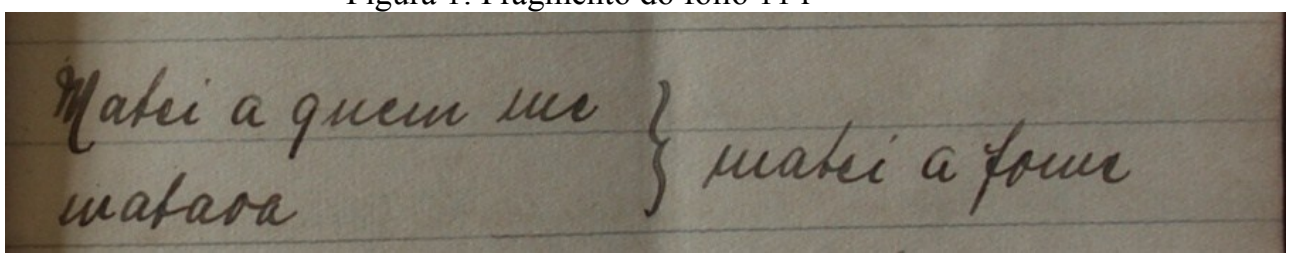

Fonte: Arquivo do Mosteiro de São Bento da Bahia 


\subsection{Colocações}

"As colocações são conjuntos de palavras que coocorrem de forma idiossincrática, no sentido de que há uma preferência por certa associação, não decorrente exclusivamente do conteúdo semântico das palavras envolvidas." (FULGÊNCIO, 2008, p. 171). Elas se diferenciam das expressões idiomáticas porque, nas colocações, pelo menos um dos termos é passível de aplicação do sentido literal e o outro é uma escolha lexical construída, arbitrária, diferente da expressão idiomática da qual tomado um termo ao pé da letra, corremos o risco de mal interpretá-la.

Figura 3: Fragmento do fólio $28 \mathrm{r}^{\mathrm{o}}$

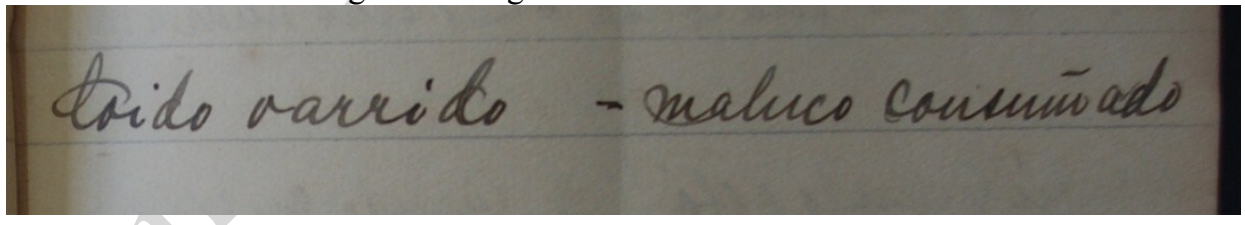

Fonte: Arquivo do Mosteiro de São Bento da Bahia

\subsection{Fórmulas Sociolinguísticas}

"Nessa categoria encontram-se as convenções lingüísticas estabelecidas na interrelação entre as pessoas. Portanto, o diferencial que caracteriza as fórmulas de trato social é uma convencionalidade no nível pragmático." (FULGÊNCIO, 2008, p.192). Esse tipo de expressão fixa é muito indicativa, ao passo que convenciona o uso em situações sociais específicas. 
Figura 4: fragmento do fólio $28 \mathrm{r}^{\circ}$

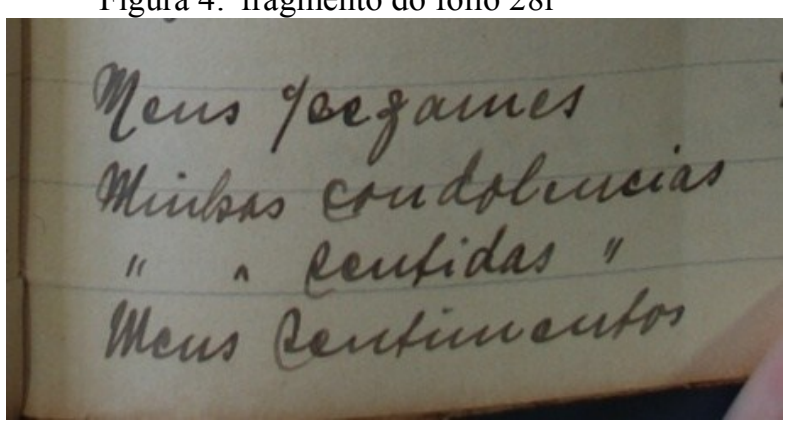

Fonte: Arquivo do Mosteiro de São Bento da Bahia

\subsection{Provérbios}

"Provérbios são frases prontas, usadas muitas vezes com sentido não-literal. Geralmente expressam uma afirmação categórica que muitas vezes encerra um conteúdo moral." (FULGÊNCIO, 2008, p. 193)

Figura 5: Fragmento do fólio 29 ro

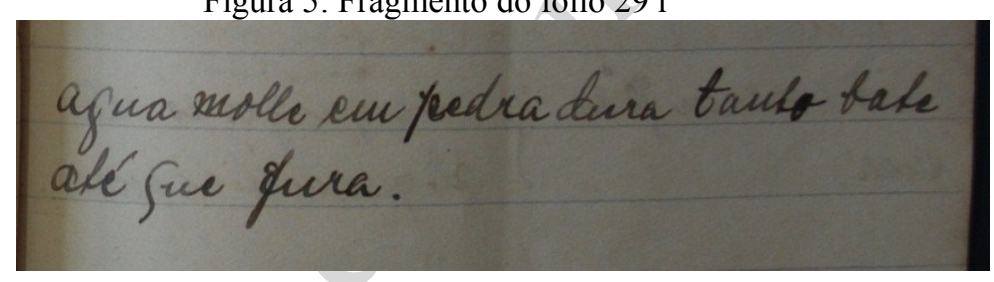

Fonte: Arquivo do Mosteiro de São Bento da Bahia

Além de expressões fixas, como as expostas acima, foram observadas algumas estruturas que abriram margem para algumas hipóteses. Antes de mostrá-las, no entanto, faremos algumas considerações a respeito do trabalho que está sendo desenvolvido, com o intuito de apontar os momentos em que as hipóteses surgiram, localizá-las nas etapas do trabalho e, a seguir, apresentar as explicações (mesmo que temporárias) e o modo como elas se relacionam com a história da criação do Códice como um todo.

\section{Do trabalho a ser desenvolvido}

A proposta de trabalho com o Códice 482 consiste em realizar uma edição conservadora do documento objetivando contribuir para estudos históricos, sociais, culturais, linguísticos, discursivos, lexicais e semânticos. Para tal, serão percorridas as seguintes etapas metodológicas: revisão bibliográfica referente ao tema, inventariação e 
digitalização de todo o documento, análise das suas características intrínsecas e extrínsecas, transcrição e, posterior, organização da edição.

Atualmente, é a etapa de transcrição que está em andamento. Essa atividade possibilita ao editor muitas descobertas, uma vez que, ali, na superfície textual, estão guardadas informações de cunho histórico-cultural que são de grande valia e cabe àquele que vai promover esse deslocamento de informações agir de forma condizente com o rigor requerido pelo trabalho filológico É pensando nessa necessidade de representar o mais fielmente possível aquilo ofertado pelo documento, que foram estabelecidos os critérios para edição expostos a seguir.

O texto será transcrito linha a linha, obedecendo à disposição do original no fólio. A transcrição será feita dentro de tabelas, cujas linhas de grade serão ocultadas; serão indicadas as numerações dos fólios e das linhas (indicando-se a cada cinco linhas, apenas aquela que apresentam mancha escrita), em coluna à esquerda. Os comentários do editor serão apresentados em nota de rodapé.

Serão mantidas, na medida do possível, as marcas gráficas utilizadas pelo próprio scriptor, as quais, muitas vezes, são iguais aos marcadores normalmente utilizados pelo Grupo de Pesquisa do Mosteiro de São Bento da Bahia. Desta forma, foi necessário fazer algumas adaptações.

São utilizados pelo próprio autor os seguintes marcadores:

- chaves \{\} : o scriptor as utiliza como uma tentativa de indicar que todas as palavras que ali estiverem contidas correspondem ao mesmo vocábulo ou expressão;

- sinal de igual ou dois traços horizontais = para indicar que a partir dali será dado o significado correspondente à expressão

- indicações entre parênteses ( ) fazem parte do sistema de escrita, é próprio do documento;

- sublinhado é utilizado pelo próprio autor para indicar que se trata de uma palavra usada em contextos mais informais ou gírias.

Para as interferências do editor, serão utilizados os seguintes marcadores:

- $\quad / * /$ indica leituras conjecturas por danos diversos 
- o uso do itálico indica desdobramento de abreviaturas

- $\mathrm{APFL}$ - anotação posterior feita a lápis

- $[\dagger]$ indica escritos não identificados

- $\quad<>$ é utilizado para indicar que o autor traçou uma linha sobre a palavra a fim de realizar uma substituição

\section{Considerações de caráter estilístico}

O convívio com o objeto de trabalho proporciona ao pesquisador uma intimidade, uma familiarização tão grande a ponto de desnudar as peças ocultas de sua constituição e mais, o sujeito produtor também começa, aos poucos, a ser revelado e denunciado por sua grafia, seu jeito particular de organizar, classificar e abreviar; suas marcas estão todas postas ali.

Para divulgar um pouco do estilo presente no Códice, traremos alguns apontamentos de nível paleográfico, além de discorrer um pouco a respeito das abreviaturas e sinalizações identificadas no decorrer das transcrições.

Entre as observações paleográficas temos:

- grafia da letra $<$ ç $>$ similar $\mathrm{a}<\mathrm{g}>$

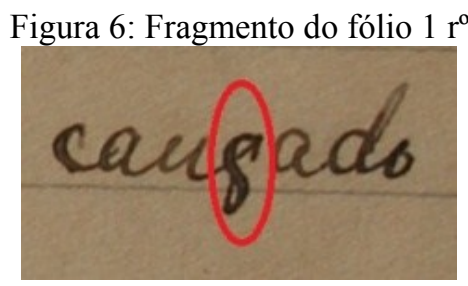

Fonte: Arquivo do Mosteiro de São Bento da Bahia

Transcrição: cançado

- grafia das letras $<\mathrm{m}>\mathrm{e}<\mathrm{n}>$ similares a $<\mathrm{w}>$ e $<\mathrm{u}>$ respectivamente

- grafia da letra $<\mathrm{t}>$ às vezes similar a um $<\mathrm{d}>$ 
Figura 7: Fragmento do fólio $4 \mathrm{r}^{\mathrm{o}}$

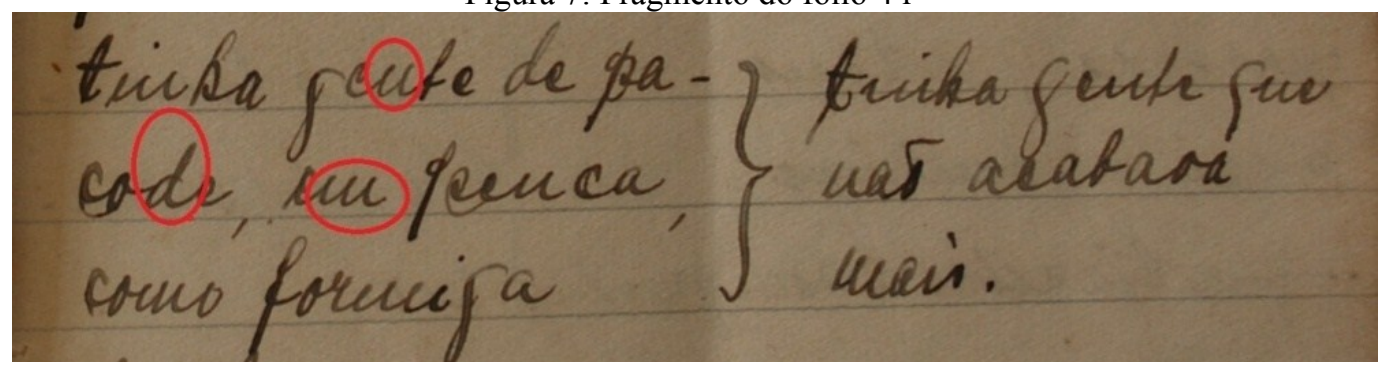

Fonte: Arquivo do Mosteiro de São Bento da Bahia

\section{Transcrição:}

tinha gente de pa - tinha gente que

$\left.\begin{array}{l}\text { cote, em penca, } \\ \text { como formiga }\end{array}\right\} \begin{aligned} & \text { não acabava } \\ & \text { mais. }\end{aligned}$

Algumas observações ao nível de organização:

$\mathrm{O}$ autor utiliza o sinal de = para indicar que dará o significado correspondente à expressão:

Figura 8: Fragmento do fólio $22 \mathrm{v}^{\mathrm{o}}$

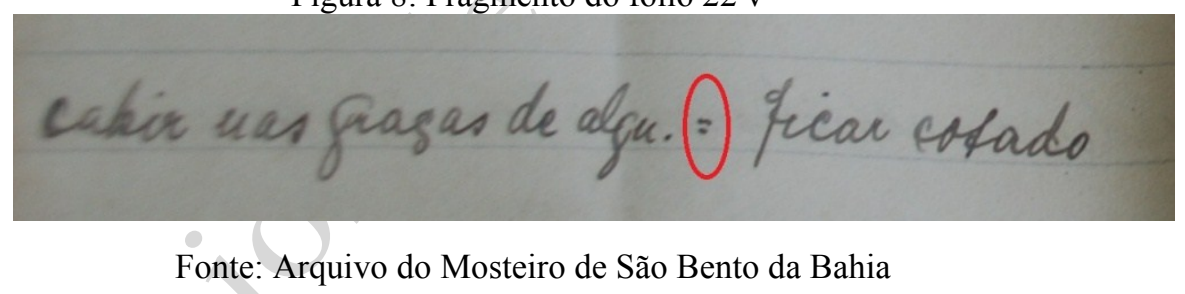

\section{Transcrição:}

Cahir nas graças de alguém $=$ ficar casado

Ou usa chaves para delimitar o que pertence a cada expressão:

Figura 9: Fragmento do fólio $6 \mathrm{r}^{\mathrm{o}}$

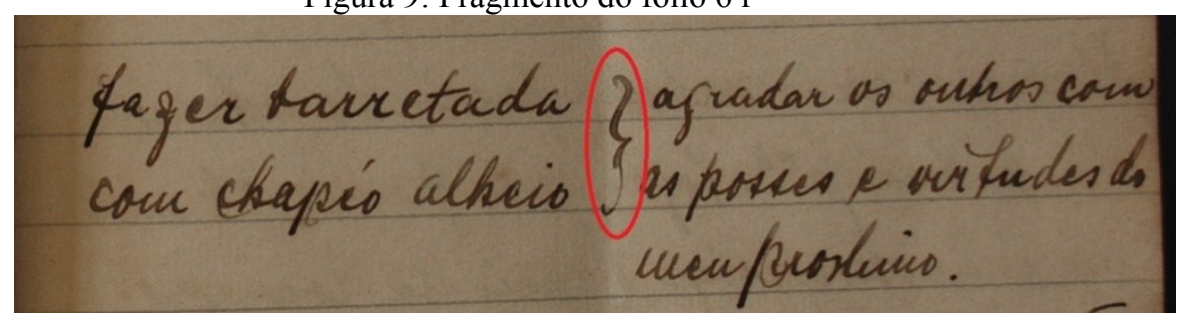

Fonte: Arquivo do Mosteiro de São Bento da Bahia 


\section{Transcrição:}
fazer barretada \}agradar os outros com com chapéo alheio as posses e virtudes do meu proximo.

Em relação às abreviaturas, elas não apresentam o referente padrão que se poderia esperar, precisam ser recuperadas através do contexto, como em:

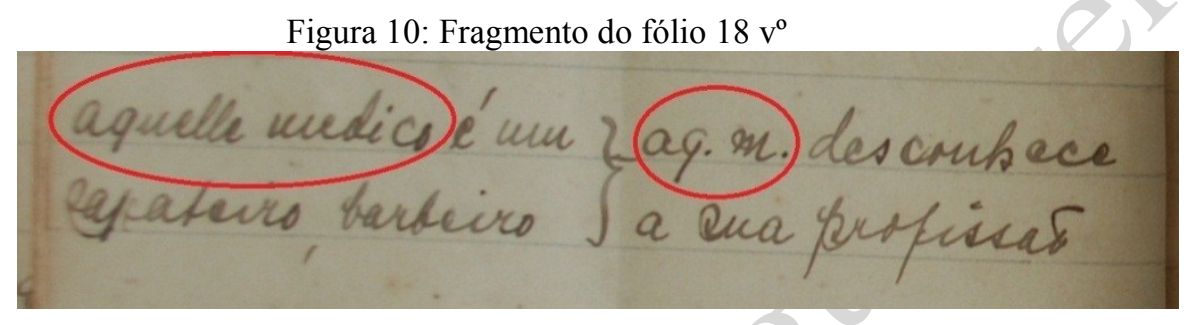

Fonte: Arquivo do Mosteiro de São Bento da Bahia

\section{Transcrição:}

aquelle medico é um łaquelle medico desconhece

sapateiro, barbeiro $\}$ a sua profissão

$\mathrm{O}$ autor utiliza ainda um recurso para sinalizar expressões que devem ser usadas em situações informais ou ainda indica entre parênteses a natureza da expressão. Observemos:

Figura 11: Fragmento do fólio $18 \mathrm{v}^{\mathrm{o}}$

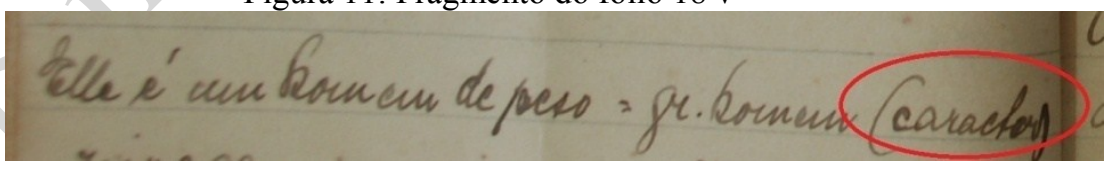

Fonte: Arquivo do Mosteiro de São Bento da Bahia

\section{Transcrição:}

Elle é um homem de peso = grande homem (caracter) 
Figura 12:Fragmento do fólio $9 \mathrm{v}^{\mathrm{o}}$

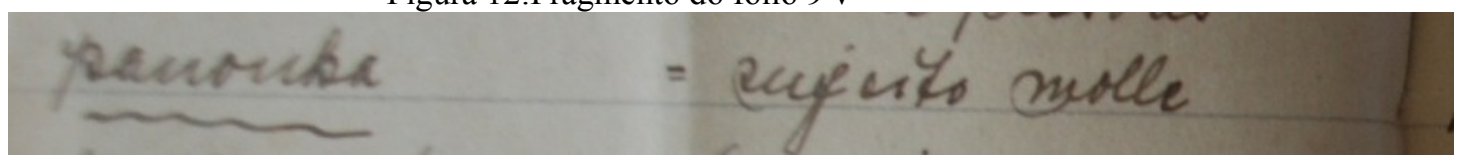

Fonte: Arquivo do Mosteiro de São Bento da Bahia

\section{Transcrição:}

pamonha $=$ sujeito molle

É importante observar as estratégias de sinalização utilizadas pelo autor do documento para entender, ou pelo menos tentar, quais eram os seus objetivos ao produzir esse material.

Como visto, foi na etapa correspondente à transcrição que começamos a observar as características exclusivas do documento buscando o máximo aproveitamento do objeto em estudo, mas, junto com elas, notou-se a presença de algumas construções que fugiam ao conteúdo da maioria do documento, que são as expressões fixas. Elas representavam algumas curiosidades em relação à cultura, ilustravam situações que nos conduzem a levantar hipóteses em relação à criação do referido glossário; trataremos dessa questão na próxima seção.

\section{Algumas descobertas, possíveis justificativas}

Antes de exibir as construções, faremos uma breve consulta ao conceito de léxico para esclarecermos a relação deste com as expressões fixas.

Quando se fala em léxico, é comum que as pessoas o associem ao conjunto de palavras de uma língua. Apesar de ser uma definição coerente, ela necessita de um complemento, conforme afirma Basílio (2009, p.09): “[...] o léxico, portanto, não é um conjunto de palavras. Como sistema dinâmico, apresenta estruturas a serem utilizadas em sua expansão [...]". Há ainda quem defenda uma ideia ainda mais expansiva do léxico, como Fulgêncio (2008, p. 60):

O conhecimento lexical possuído pelos falantes inclui não somente informações a respeito de elementos monomorfêmicos ou de palavras polimorfêmicas, mas precisa incluir informações sobre construções idiossincráticas, ou seja, estruturas formadas por várias palavras em seqüência. (grifo do autor) 
O caráter dinâmico do léxico, em que, ao mesmo tempo que algumas palavras estão entrando em desuso, outras estão sendo criadas ou tomadas de empréstimo; e tendo em vista que "[...] o léxico de uma língua natural constitui uma forma de registrar o conhecimento do universo [...]" (BIDERMAN, 1998, p. 11), é primordial atentar para a relação indissociável entre léxico, cultura e história: afinal é por via da linguagem que o homem se comunica e essa é expressa em palavras que, por sua vez, constituem o sistema lexical.

Agora que já está claro o que vem a ser léxico e sabendo que as expressões fixas também fazem parte dele, um questionamento é levantado: como as expressões fixas são armazenadas na memória do falante?

Para responder a essa questão a colocação de Fulgêncio $(2008$, p. 62) se mostra bastante oportuna:

[...] a estrutura de uma expressão fixa é disponível ao usuário da língua a partir de duas fontes, simultaneamente: o armazenamento em bloco e a aplicação das regras [...]. O que se pretende dizer é que o falante tem na memória, ao mesmo tempo, a expressão fixa e a estrutura esqueletal da qual a expressão é um exemplo de realização (no caso de expressões que seguem os parâmetros sintáticos).

Isso significa que o falante precisa memorizar as expressões e lembrar que elas não são decomponíveis.

Depois desse breve passeio entre os domínios do léxico, apresentaremos as construções que foram identificadas no códice.

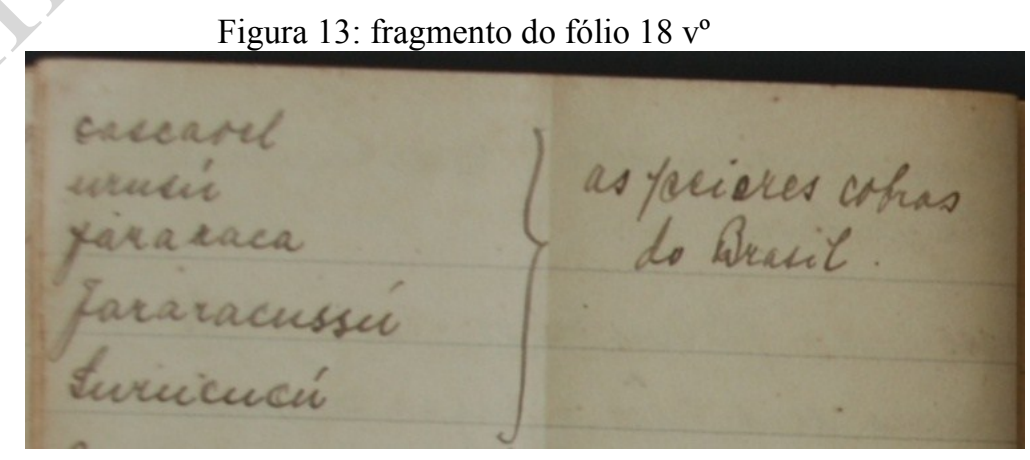

Fonte: Arquivo do Mosteiro de São Bento da Bahia 


\section{Transcrição:}

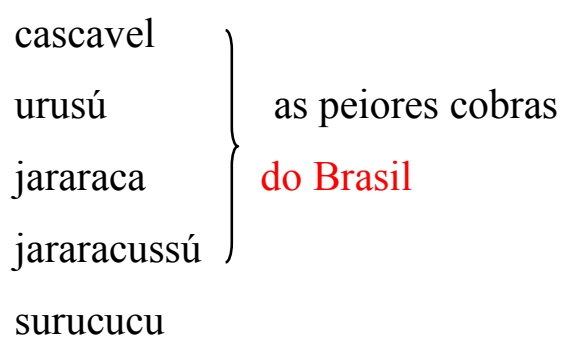

Figura 14: Fragmento do fólio $24 \mathrm{r}^{\mathrm{o}}$

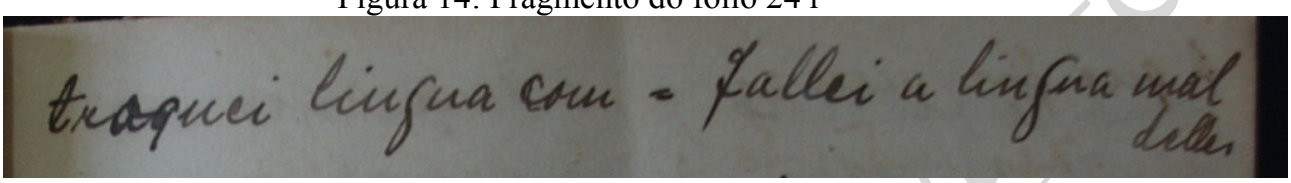

Fonte: Arquivo do Mosteiro de São Bento da Bahia

\section{Transcrição:}

troquei língua com = fallei a lingua mal

$$
\text { delles }
$$

Figura 15: Fragmento do fólio $31 \mathrm{v}^{\mathrm{o}}$

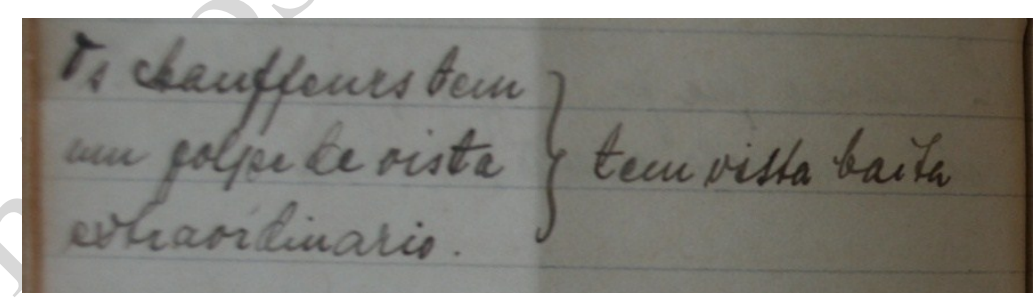

Fonte: Arquivo do Mosteiro de São Bento da Bahia

\section{Transcrição:}

Os chauffeurs tem $\left.\begin{array}{l}\text { um golpe de vista } \\ \text { extraordinário }\end{array}\right\}$ tem vista baita 
Ele utiliza uma palavra de origem francesa para designar motoristas. Tal uso, no entanto, não se configura como diferencial deste documento, já que os galicismos eram correntes à época.

Figura 16: Fragmento do fólio $26 \mathrm{r}^{\mathrm{o}}$

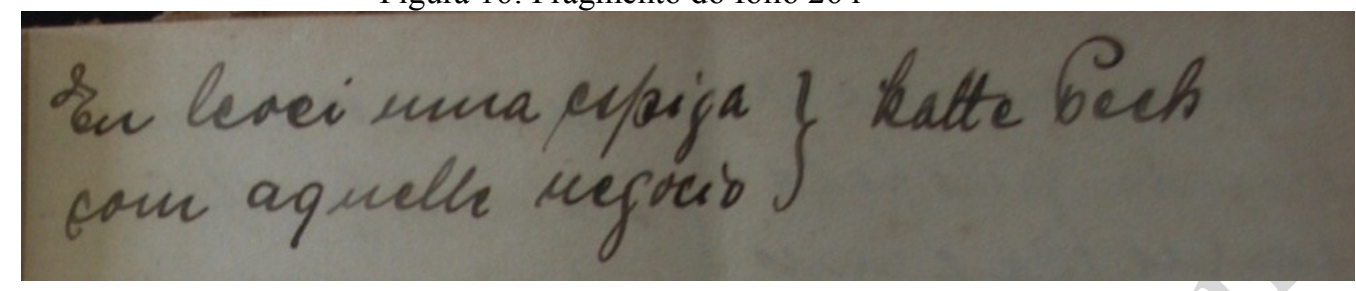

Fonte: Arquivo do Mosteiro de São Bento da Bahia

\section{Transcrição:}

$\left.\begin{array}{l}\text { Eu levei uma espiga } \\ \text { com aquelle negocio }\end{array}\right\}$ hatte Pech

Dessa vez o autor se vale de uma expressão de origem alemã para fazer correspondência à construção em língua portuguesa. A expressão em alemão indica algo relacionado à falta de sorte, azar.

Figura 17: Fragmento do fólio $25 \mathrm{v}^{\mathrm{o}}$

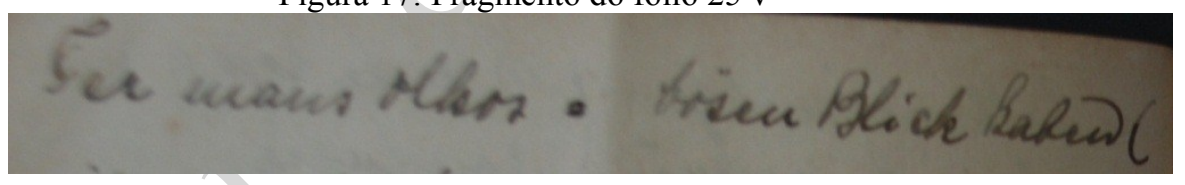

Fonte: Arquivo do Mosteiro de São Bento da Bahia

\section{Transcrição:}

Ter maus olhos $=$ bösen Blick haben

E essa estratégia se repete, faz uso da expressão alemã, que significa "ter mau olhado", como correspondente à expressão "ter maus olhos" em português.

Diante desses exemplos, a primeira hipótese levantada é a de que o monge responsável pela confecção desse códice não seja um falante nativo de língua portuguesa, uma vez que, ao ter dificuldade de entender uma sentença, a primeira estratégia que se usa, geralmente, é aproximar o item desconhecido de um componente 
que seja do seu conhecimento para fazer associações e conseguir compreender do que se trata. Conforme afirma Fulgêncio (2008, p. 131):

No primeiro contato com a EF, quando o significado idiomático não é conhecido, o ouvinte/leitor tem de atuar na produção do sentido. Isso acontece por exemplo quando se aprende uma língua estrangeira. Nesse caso há duas possibilidades de aquisição da EF:

a) ou o aprendiz incorpora o sentido da expressão como um todo, sem decodificação de suas partes, assim como aprende o significado de uma palavra da língua;

b) ou o aprendiz constrói alguma relação que justifique e ampare o sentido idiomático da EF.

Parece que a estratégia utilizada pelo sujeito se enquadra na segunda possibilidade, já que ele busca, por via da comparação, estabelecer uma correspondência entre uma expressão que ele domina e a outra até então desconhecida; ainda com Fulgêncio (2008, p. 132) percebe-se que:

No caso do aprendizado de uma segunda língua, o aprendiz adulto tem uma atitude analítica diante da L2, e muitas vezes procura estabelecer regras e generalizações que o ajudem na construção da interlíngua, ou uma lógica interna que organize os conhecimentos.

Corrobora a hipótese da nacionalidade do autor o fato de o Mosteiro da Bahia ter recebido, no início do séc. XX, diversos monges alemães.

\section{O caminho escolhido}

Vale a pena salientar que o monge responsável pela confecção do códice não o intitula com o termo glossário; essa terminologia foi aplicada aqui como forma de situar o objeto de estudo. O autor utiliza o termo Notas para designar esse conjunto de expressões listadas; sendo assim, é de fundamental importância refletir a respeito dessa denominação.

Uma consulta ao dicionário de Caldas Aulete oferece, dentre outras acepções, a seguinte: “[...] anotação, marca feita para lembrar, registrar ou comunicar algo.” É sobre a passagem "marca feita para lembrar" que queremos nos debruçar em especial.

Quando fazemos uma anotação, geralmente queremos salvaguardar, por meio da escrita, algo que consideramos importante. A anotação, por ser uma modalidade escrita, 
tem esse caráter de fixar, por intermédio das palavras, as ideias e os pensamentos. Ela figura como uma espécie de "porto seguro", em caso de lapsos mnemônicos.

Logo, é perceptível que as notas também podem se configurar como um exercício de aprendizagem, um meio de assimilação seguro, falando em especial das expressões fixas que precisam ser memorizadas em bloco no léxico mental do falante; como já vimos, não seria surpreendente que alguém optasse por fazer uso dessa modalidade para aprendê-las.

Podemos supor, então, a motivação da criação deste glossário de expressões cotidianas: o desejo de compreender, por meio das expressões fixas e, consequentemente, do léxico, o universo novo a que o sujeito estava submetido. Talvez ele não tenha tido a intenção de criar um glossário, mas apenas listar algumas expressões que, por serem próprias de um universo linguístico diferente do dele, tornavam-se obscuras, exatamente como algumas passagens dos textos de Homero e Cícero que necessitavam de glosas (para respeitar a terminologia do usuário daquelas Notas, para serem compreendidas).

Dessa forma, é possível observar que o glossário não foi criado como um fim, necessitando de um árduo trabalho de depuração lexicográfica, como fazem os lexicógrafos, mas como um meio, um instrumento de aprendizagem que acabou por nos trazer grandes contribuições, pois o que se encontra ali guardado na superfície textual não é uma mera coleção de estruturas lexicais, são ferramentas que constituem um tesouro cultural, nas palavras de Biderman (1998, p. 12): “[...] o patrimônio vocabular de uma dada comunidade linguística [...]" que inevitavelmente desvela a sua cultura e sua história, afinal:

Estudar o léxico de uma língua é enveredar pela história, costumes, hábitos e estrutura de um povo, partindo-se de suas lexias. É mergulhar na vida de um povo em um determinado período da história, através do seu léxico. Apesar de pouco estudado até então, o estudo lexical das línguas é deveras importante e necessário para desvendar os inúmeros segredos da nossa história social e lingüística, segredos estes que podem ser desvendados pelo estudo e análise do léxico existente nessas línguas em momentos específicos da história de cada povo. Língua, história e cultura caminham sempre de mãos dadas e para conhecermos cada um desses aspectos, faz-se necessário mergulhar nos outros, pois nenhum deles caminha sozinho e independente. Portanto, o estudo da língua de um povo, é conseqüentemente, um mergulho na história e cultura deste povo. (ABBADE, 2011, p.01) 
Enfim, pode ser que a nossa hipótese se confirme e o documento realmente seja um caminho para compreender uma realidade cultural, ou, pode ser que tenhamos caído na esparrela... O importante é não entregar os pontos e continuar nesse jogo fascinante que envolve o trabalho com arquivo onde:

[...] Os elementos estão todos ali, uns mais a mostra, outros menos, de tempos em tempos a estes se juntam outros, mas assim como um quebra-cabeças as peças vão se reunindo aos poucos, com a diferença que cada uma delas pode se agrupar com diversos elementos para formar novas figuras (LOSE, 2004)

\section{Referências}

ABBADE, C. M. de S.. A Filologia e o estudo do léxico. Disponível em: $<$ http://www.filologia.org.br/ileel/artigos/artigo_244.pdf >. Acesso em 31 out. 2011.

ALMEIDA, A. A. D.. Filologia: uma linha para a Lexicologia tecer os seus pontos. In: TEIXEIRA, M. da C. R.; QUEIROZ, R. de C.; SANTOS, R.B. dos (Org.). Diferentes perspectivas dos estudos filológicos. Salvador: Quarteto, 2006. p. 227-240.

BARBOSA, M. A. Dicionário, vocabulário, glossário: concepções. In: ALVES, I. M. (Org.). A constituição da normalização terminológica no Brasil. São Paulo: FFLCH/USP, 1996.p.23-45.

BASÍLIO, M. Formação e classes de palavras no português do Brasil.2. ed. São Paulo: Contexto, 2009. p.1-11.

BIDERMAN, M. T. C. As ciências do léxico. In: OLIVEIRA, A. M. P. P.; ISQUERDO, A. N. (Org.). As ciências do léxico: lexicografia, lexicologia, terminologia. Campo Grande: UFMS, 1998. p. 11-20.

FULGÊNCIO, L. Expressões fixas e idiomatismos do português brasileiro. Tese de Doutoramento em Letras. Pontifícia Universidade Católica de Minas Gerais. Belo Horizonte, 2008.

HAENSCH, G. "Tipología de las obras lexicográficas e Aspectos prácticos de la elaboración de diccionarios”. In: ETTINGER, S. et al. La lexicografía. De la lingüística teórica a la lexicografia prátctica. Madrid: Gredos, 1982. Apud BARBOSA, M. A. "Dicionário, vocabulário, glossário: concepções". In: ALVES, I. M.. (Org.). A 
constituição da normalização terminológica no Brasil. São Paulo: FFLCH/USP, 1996. p. 23-45.

LOSE, A. D.. Arquivo: a morada da censura. Inventário. Revista dos alunos do PPGLL da UFBA. n. 1. v. 1, 2004. Salvador. Disponível em: $<$ http://www.inventario.ufba.br/02/02alose.htm>. Acesso em: 29 out. 2011.

MULLER, C.. Initiation à la statistique linguístique.Paris: Larousse, 1968. Apud BARBOSA, M. A.. Dicionário, vocabulário, glossário: concepções”. In: ALVES, I. M. (Org.). A constituição da normalização terminológica no Brasil. São Paulo: FFLCH/USP, 1996. p. 23-45.

NUNES, J. H. Dicionários no Brasil: análise e história do século XVI ao XIX. Campinas, SP: Pontes, 2006. p. 15-58.

Artigo recebido em: 30.03 .2012

Artigo aprovado em: 26.06.2012 